\section{A STUDY IN LOCOMOTION}

III.

I $T$ would be very interesting to pass in review the 1 principal epochs of art and trace out the manner of representing horses in motion in various periods of progress or decadence. But such a study would fail to realise its full value unless carried out by an artist.

Col. Duhousset, who joins the skill of the draughtsman to a perfect acquaintance with the exterior of the horse, has essayed a work of this kind, and in a recent publica-

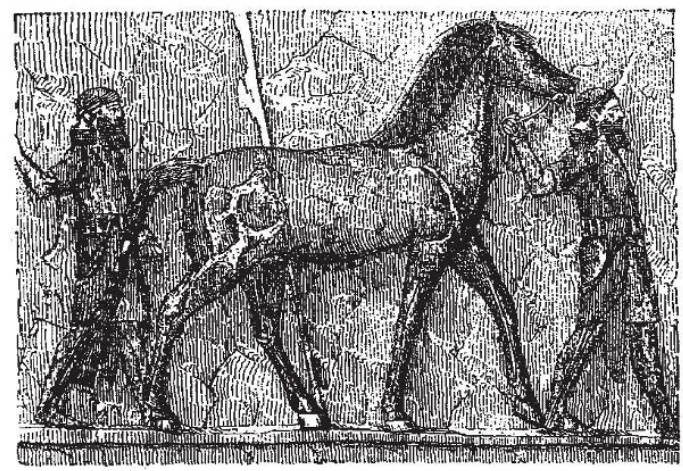

FIG. 20.-Assyrian bas-relief (Brit'sh Museum). A horse ambling.

tion has pointed out the merits and defects of certain modern artistic performances. M. Duhousset has also gathered together a curious collection of representations of the horse at different epochs of art, and has entrusted to me a few specimens, which I will now exhibit to you. You will see that in a general manner art has progressed, proceeding from simple forms to more masterly delineations.

Figs. 20 and 2I represent horses ambling. Has the artist selected this pace because it was in general use at

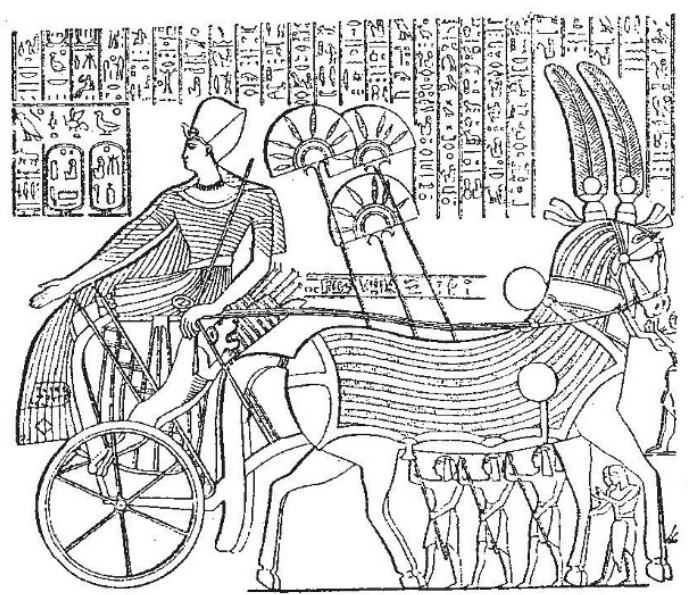

FIG. 2x.-Egyptian tas-relief (Medinet-Abou). Two horses attacked to a chariot, and ambling.

that time? This is scarcely probable; it would seem more likely that he has chosen it because of its extreme simplicity. To seize the moment when the four feet all touch the ground, to repeat in the posterior limbs the attitude of the limbs in front, and, lastly, to represent all the horses harnessed together as keeping exact time in

* "Moteurs animés; Exfériences de Physiolog.e grafhique." Lecture "Moteurs animés; Exfériences de Physiolog.e grafhique." Lecture
by Prof. Marey at the Paris meeting of the French Association, August 29, $88_{7} 8$. Continued from p. $4^{6} ;$. their movements so as to draw them all with a single

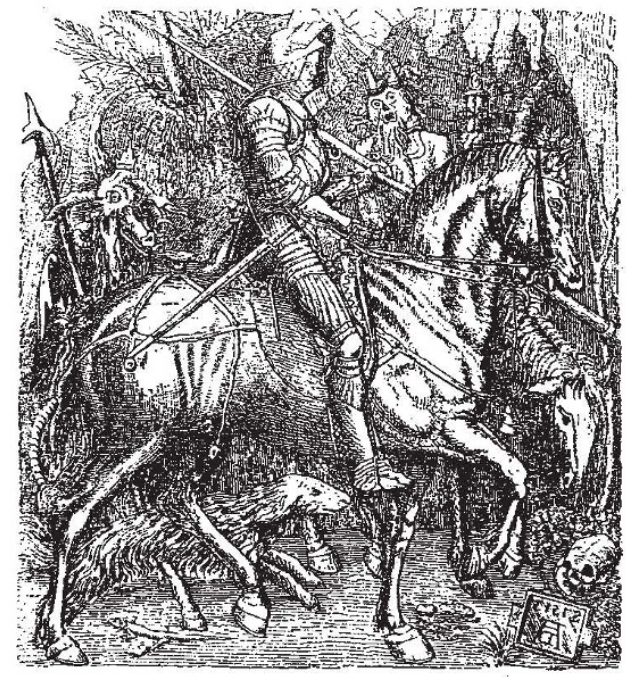

FIG. 22.- " "The Cavalier and Death," by Albrecht Dürer. Horse at the trot, profile : this is certainly one way of eluding all the diffculties of the situation.

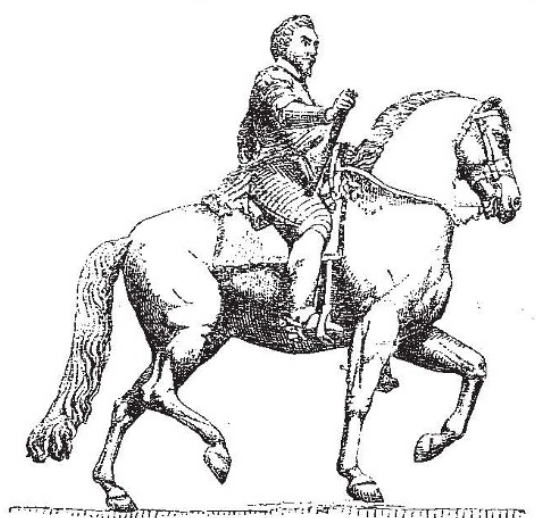

F:G. 23.-Statue of Henri IV. on the Pont Neuf. Example of the correct trot.

The pace of the trot, correctly represented in the

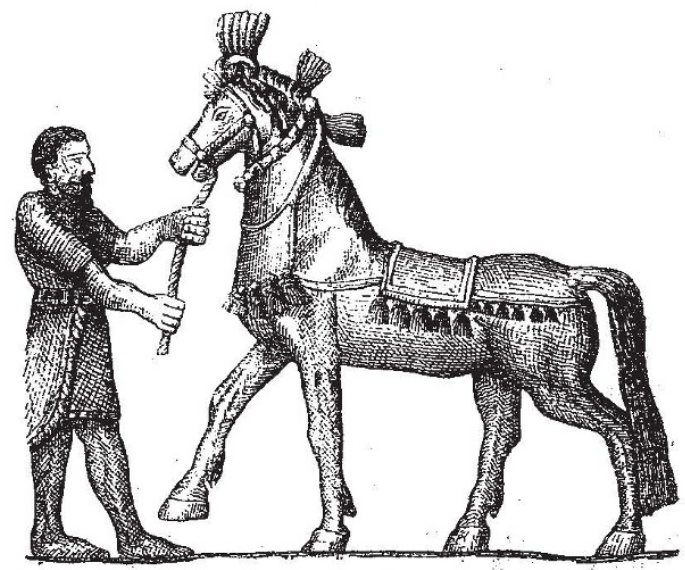

FIG. 24.-Assyrian bas-relief. Fost-pace.

Roman eroch, in the equestrian statues of the Baibi 
which adorn the Naples Museum, reappears in the six-

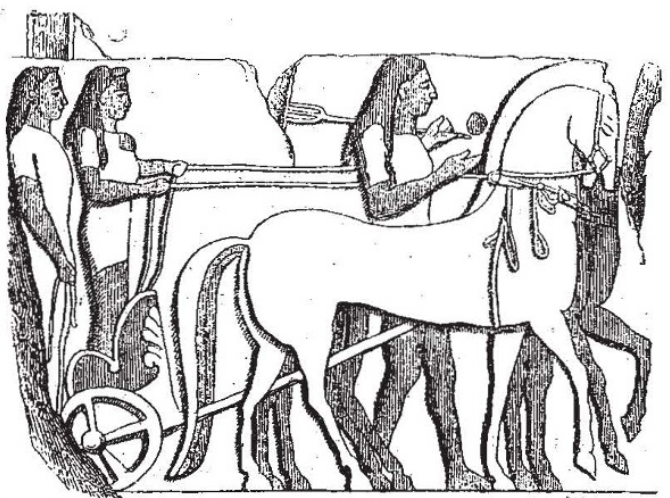

F!g. 25.- Bas-relief in baked earth, of the Volscian epoch (Velletri). Three horses harnessed together, walking at a foot-pace.

teenth century in a painting by Albrecht Dürer (Fig. 22,

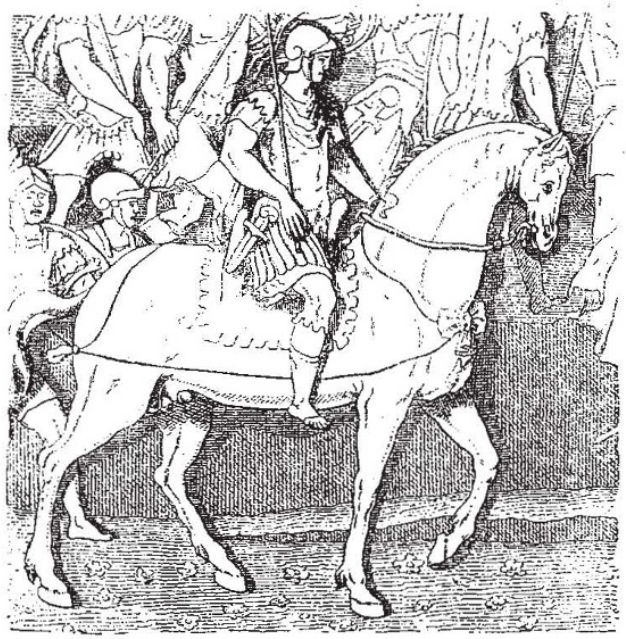

FIG. 26.-Captain of the Guards riding at a foot-pace. (Column of Trajan.)

"The Cavalier and Death"). The classic statue of

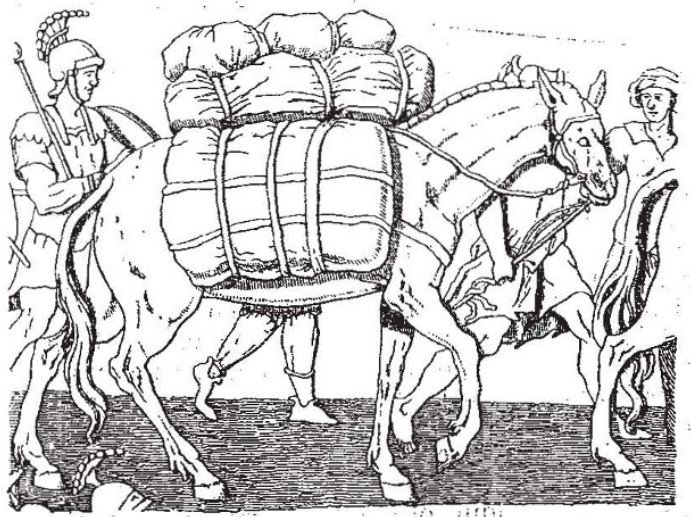

FrG. 27.-Mule laden with baggage, walking at a foot-pace. (Column of
Trajan.)

Henri IV. on the Pont Neuf is an example of the correct trot (Fig. 23).
But the representation of the foot-pace, more difficult than the preceding, is rarely faithful. Examples, scarcely satisfactory, are found in all the epochs; take, for instances, Figs. 24 and 25.

The foot-pace is correctly represented in the two figures borrowed from the column of Trajan (Figs. 26 and 27). This column also displays oxen and other animals faithfully represented.

These paces, it should be noted, are a little varied with respect to the instant chosen; almost invariably the horse raises only one fore-foot.

The gallop is in general the pace of which the representation leaves most to be desired. Without speaking of contemporary art, I will refer only to the paintings of the two or three last centuries. The horses therein deemed to be galloping are represented in a sort of prancing attitude, posed upon the two hind-feet, and raising the two fore-feet to an equal height. We have seen, by the preceding notations, that this synchronous action of the right and left limbs does not exist.

In the grandest epoch of Greek art we find admirable representations of the gallop. Fig. 28 is an example. The attitude chosen is the first step of the gallop as in Fig. 16. The first step has been taken. The diagonal

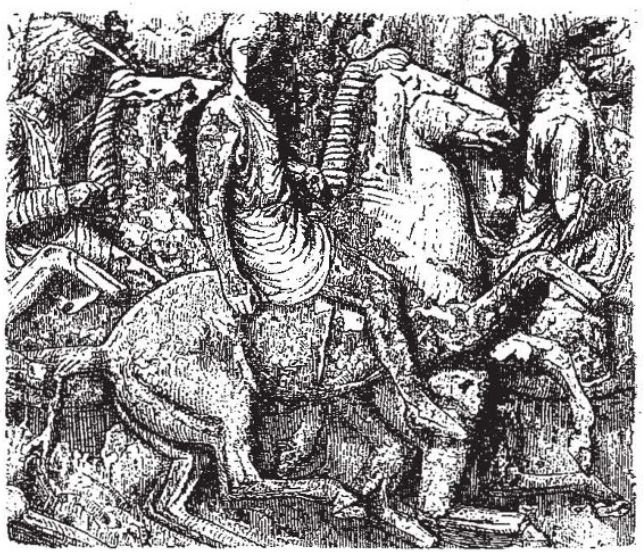

FIG. 28.-Frieze of the Parthenon. (Bas-relief remaining at Athens.) Right hand gallop.

limbs which make the second step are approaching towards the ground, and the right hand fore-foot which will make the last step is held high in air.

I have already admired the reproduction in plaster of another bas-relief from the same frieze, in which a galloping horse is represented with equal correctness, and I was led to belieye that in the age of Phidias, artists were in possession of the science of paces. But subsequently, in examining the reproductions of the entire frieze, I have become convinced that the results were obtained by a happy chance, for the greater part of the horses are represented in false attitudes, which is all the more to be regretted in contemplating the exquisite elegance of their forms.

It is incontestable that at the present day, artists make great efforts to represent the horse with truthfulness, and many among them succeed. But $I$ will not permit myself to criticise the works of my contemporaries. Such, then, is the graphic method, and such are its numerous applications, extremely varied, and often of enormous importance. In this discourse, the length of which you will excuse, I have only shown you a little corner of the subject, but that will suffice, I hope, to give you a desire to study more deeply, and in its entirety, a method which appears to me to be full of promise, and to the development of which I have already consecrated much effort. 